\title{
Physical rehabilitation in the awake patient receiving extracorporeal circulatory or gas exchange support
}

\author{
Michael Salna ${ }^{1}$, Darryl Abrams ${ }^{2}$, Daniel Brodie ${ }^{2}$ \\ ${ }^{1}$ Division of Cardiothoracic Surgery, Department of Surgery, Columbia University Irving Medical Center, New York, NY, USA; ${ }^{2}$ Division of \\ Pulmonary, Allergy, and Critical Care Medicine, Department of Medicine, Columbia University Medical Center, New York, NY, USA \\ Contributions: (I) Conception and design: All authors; (II) Administrative support: None; (III) Provision of study materials or patients: None; (IV) \\ Collection and assembly of data: All authors; (V) Data analysis and interpretation: All authors; (VI) Manuscript writing: All authors; (VII) Final \\ approval of manuscript: All authors. \\ Correspondence to: Daniel Brodie, MD. Professor of Medicine, Division of Pulmonary, Allergy, and Critical Care Medicine, Department of Medicine, \\ Columbia University College of Physicians and Surgeons, NewYork-Presbyterian Medical Center, New York, NY, USA. Email: hdb5@cumc.columbia.edu.
}

\begin{abstract}
Intensive care unit (ICU)-acquired weakness is a common and serious sequela of critical illness. There is a growing body of evidence supporting the use of early mobilization in the ICU to mitigate this adverse effect. Recent data suggest that such a strategy may be feasible in patients with the most severe forms of cardiopulmonary failure-those requiring temporary mechanical circulatory support (TCS) or extracorporeal life support (ECLS). Both the modality of mechanical support and patientspecific characteristics must be taken into consideration when determining the appropriateness of an early mobilization strategy. The purpose of this review is to explore the current understanding of and evidence for mobilization and rehabilitation of patients receiving TCS or ECLS, including the identification of factors that may predict greater success for early mobilization and potential risks and contraindications to active physical therapy. While it is not yet known which of these patients are most likely to benefit from physical rehabilitation, a common theme is the importance of an interprofessional team approach to ensure patient safety and maximize the likelihood of successful mobilization.
\end{abstract}

Keywords: Extracorporeal membrane oxygenation (ECMO); extracorporeal life support (ECLS); rehabilitation; ambulation

Submitted Dec 05, 2019. Accepted for publication Mar 09, 2020.

doi: $10.21037 / \mathrm{atm} .2020 .03 .151$

View this article at: http://dx.doi.org/10.21037/atm.2020.03.151

\section{Introduction}

Intensive care unit (ICU)-acquired weakness is a serious sequela of critical illness and may persist long after the resolution of the original illness (1). Invasive mechanical ventilation (IMV), sedation, and corticosteroids are among the factors associated with neuromuscular dysfunction in patients with cardiopulmonary failure (2). Immobility is a significant and potentially modifiable contributor, with experimental studies of even healthy subjects experiencing up to a $5 \%$ loss of muscle strength for each week of bed rest (3).

There has been a paradigm shift in intensive care medicine as a growing body of literature highlights the benefits of minimizing sedation, identifying and modifying potential risk factors for weakness in the ICU and engaging in early physical therapy. Several studies have suggested that early mobilization in the ICU may improve overall lengths of stay, rates of delirium, ventilator-free days, and potentially ICU survival (4-6). Indeed, a 2017 systematic review that included over 22,000 mobilization sessions of ICU patients demonstrated an excellent safety profile with an adverse event rate of only $0.6 \%$, and a subsequent metaanalysis demonstrated that active ICU rehabilitation was associated with improved ambulation, and more days alive and out of the ICU at 6 months $(5,7)$. These promising 
Table 1 Advantages, disadvantages, and rehabilitation considerations TCS/ECMO

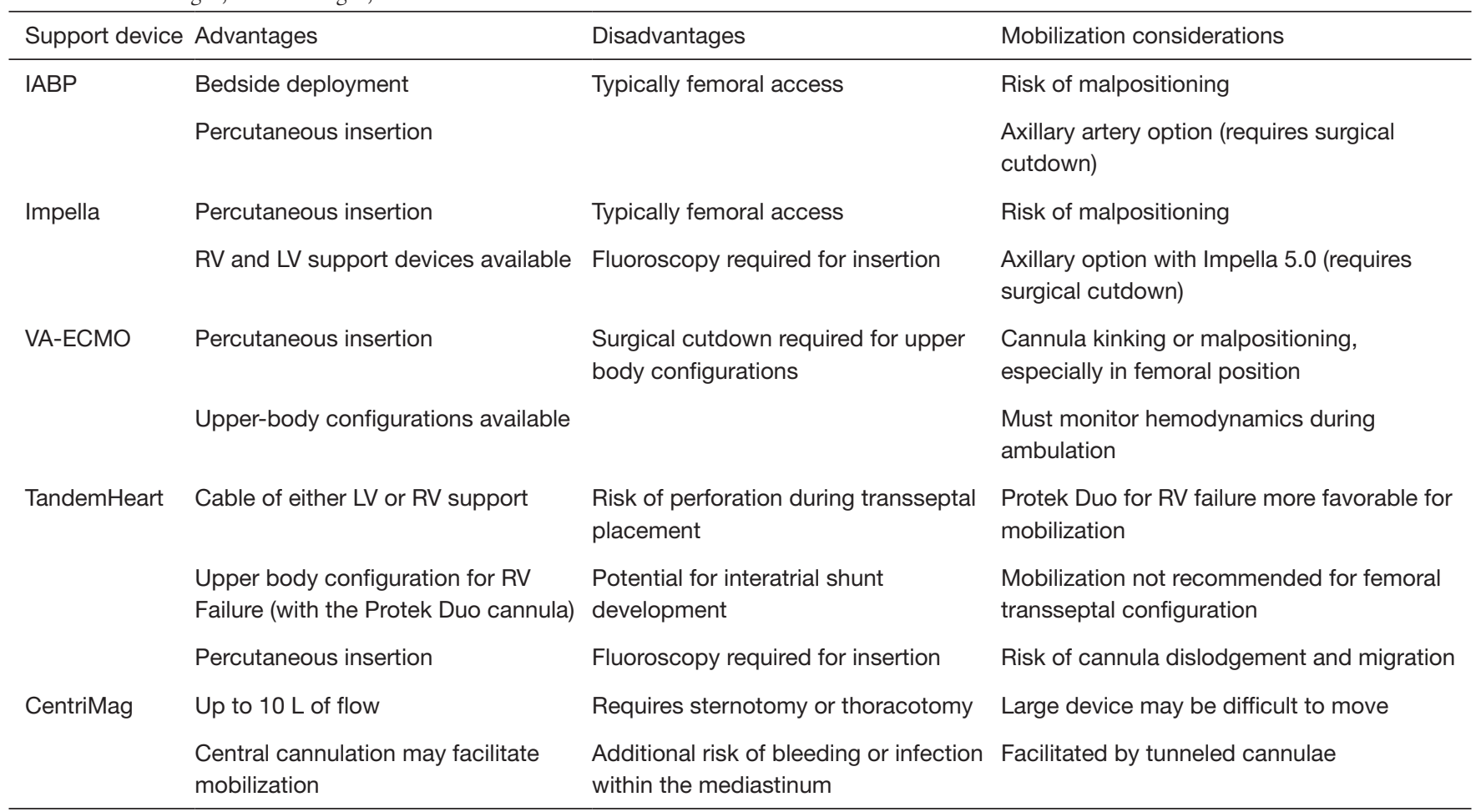

IABP, intra-aortic balloon pump; VA-ECMO, venoarterial extracorporeal membrane oxygenation; RV, right ventricle; LV, left ventricle; TCS, temporary mechanical circulatory support.

data among the general critical care population have raised the question of whether such a strategy could or should be extended to patients who potentially are at great risk for the development of ICU-acquired weakness-those receiving temporary mechanical circulatory support (TCS), including extracorporeal life support (ECLS) for circulatory support but also for gas exchange support, for the most severe forms of cardiopulmonary failure. Whether bridging to recovery, a left ventricular assist device (LVAD), heart or lung transplantation, or bridging to a decision, this strategy-if performed safely in appropriately selected patients—might be expected to improve overall outcomes.

The purpose of this review is to explore the current understanding and evidence for mobilization and rehabilitation of patients receiving TCS and ECLS, including patient- and circuit-specific factors that may allow for greater success for early mobilization, as well as potential risks and contraindications to active physical therapy.

\section{Temporary circulatory support devices and ECLS}

A variety of TCS devices are available to support patients in cardiogenic shock, ranging from the percutaneously placed intra-aortic balloon pump (IABP) to surgically implanted temporary LVADs, such as the CentriMag (Abbott, Chicago, IL) (Table 1). All of these devices serve a specific purpose in the continuum of mechanical therapies for cardiogenic shock and each has their own unique challenges during physical rehabilitation. ECLS may be used as a form of TCS, or may also be used for patients with severe respiratory failure.

\section{Intra-aortic balloon pump}

The IABP is a percutaneous device, positioned into the descending aorta, which provides hemodynamic support through counter-pulsation-augmenting diastolic pressure and coronary perfusion through inflation during diastole and reducing afterload through rapid deflation in systole. Though often inserted through the common femoral artery, these pumps may also be placed in the axillary or subclavian artery in patients requiring extended support to facilitate ambulation, particularly in the context of bridging to transplantation. Estep et al. reported a high rate of malpositioning with the axillary IABP secondary to 
this enhanced mobility. However, they reported that the device could be safely repositioned at the bedside with no significant acute adverse events (8).

\section{Percutaneous ventricular assist devices}

While the IABP provides indirect hemodynamic support through counter-pulsation, the Impella (Abiomed, Danvers, MA) provides direct hemodynamic support using continuous flow via a microaxial pump that may be inserted across the aortic or pulmonic valves for direct left or right heart support, respectively. Inserted under fluoroscopy, the pump sits inside the left ventricle (LV) - in the more common left heart support configuration-draining blood through a ventricular cannula and ejects it across the aortic valve, thereby increasing cardiac output and unloading the ventricle. Similar to the IABP, left-sided Impellas are traditionally inserted percutaneously through the common femoral artery and thereby limit ambulation due to the risk of malposition in this area. The Impella 5.0, however, offers the option for higher blood flow rates and is inserted through the axillary or subclavian artery via a surgical cutdown, which may better facilitate mobilization (9).

Percutaneous assist devices are also available with extracorporeal pumps to provide either LV or right ventricular (RV) support. The TandemHeart (LivaNova, UK) is an extracorporeal continuous flow centrifugal pump that can provide either left or RV support depending on cannulation configuration. Using a transseptal cannula, the device drains blood from the left atrium and reinfuse it via the femoral artery for LV support (10) or, can provide RV support when configured with the Protek Duo (LivaNova, UK) cannula, a dual lumen cannula inserted via the right internal jugular vein, which provides bicaval drainage and reinfusion into the pulmonary artery (11). This ProtekDuo configuration for RV failure may better facilitate mobilization than traditional surgical RV assist devices, and can even be used in acute RV failure after LVAD implantation (12).

\section{Extracorporeal life support}

ECLS is divided into extracorporeal membrane oxygenation (ECMO) and extracorporeal carbon dioxide removal (ECCO2R). ECMO has the ability to provide gas exchange and circulatory support for patients with severe respiratory or cardiac failure. Broadly speaking, the circuit consists of a venous drainage cannula from which venous blood is removed before passing through an extracorporeal centrifugal pump. This pump pushes the deoxygenated venous blood through an oxygenator whereby oxygen from a gas supply diffuses across a semipermeable membrane into the blood while carbon dioxide diffuses out of the blood. The now-oxygenated and decarboxylated blood returns to the patient through a reinfusion cannula in either a vein (venovenous ECMO), which provides gas exchange without direct hemodynamic support, or an artery (venoarterial ECMO), which provides direct hemodynamic support in addition to gas exchange (13).

\section{Temporary surgical ventricular assist devices}

The CentriMag is an extracorporeal TCS device, with surgically implanted central cannulation, which is capable of providing higher blood flow rates than the percutaneous TCS devices. It can be implanted to provide left or RV support with cannulation of the left atrium to aorta or right atrium to pulmonary artery, respectively. Ambulation in patients requiring CentriMag ventricular assist devices (VADs) has been demonstrated to be safe and feasible but the evidence largely consists of case series and case reports (14-16).

\section{Patient selection for physical rehabilitation during TCS}

Whether patients receiving TCS should be considered for active physical therapy, the timing of physical therapy, and which patients are most likely to benefit remain areas of ongoing investigation (17). Determining the appropriateness of mobilization depends on several factors: the intention of mechanical support, either bridging a patient to recovery (BTR), to a long-term VAD (bridge to decision or bridge to VAD), or to transplantation (BTT), the position/location of the TCS or the ECMO cannulation configuration, the severity of illness of the patient and their ability to participate in physical therapy are also key factors.

Most of the data from mobilization in patients receiving TCS comes from the ECMO literature. Moreover, the majority of these data in patients receiving ECMO for cardiogenic shock, specifically, derive from small case series and case reports, owing in part to the high acuity and severity of illness in this population, along with often uncertain outcomes regarding their potential to recover, receive a long-term $\mathrm{VAD}$, or undergo heart transplantation. Finally, respiratory ECMO runs tend to be longer, on average, than cardiac runs in potentially viable patients. In light of this, much of the data informing early mobilization 
Page 4 of 10

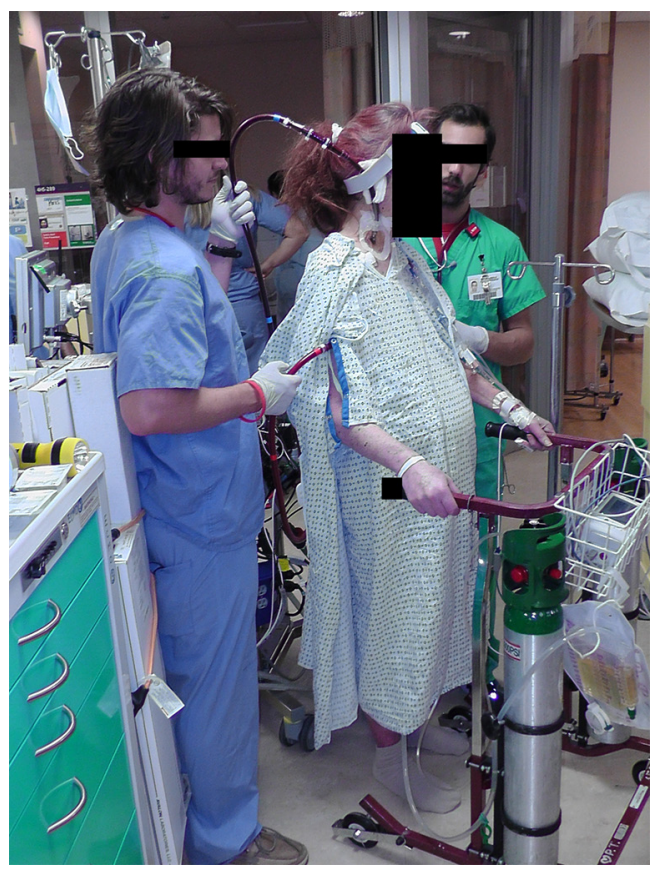

Figure 1 Awake, ambulatory patient with an upper-body configuration of venovenous extracorporeal membrane oxygenation for gas exchange support.

in ECMO patients is derived from the literature of patients receiving ECMO for severe respiratory failure. While extrapolation of this data to the cardiac population receiving mechanical circulatory support should be done with caution, clearly the data from the respiratory failure ECMO population may be informative.

\section{Bridge to transplantation}

The rationale for mobilization of patients receiving TCS may be strongest for those awaiting heart transplantation, in so far as it is analogous to bridge to lung transplantation, where physical deconditioning is a relative contraindication to transplantation because of a decreased ability to survive and recover from the transplantation itself (18). For example, immobilized patients receiving venovenous ECMO as bridge to lung transplantation have been shown to be at greater risk for developing ICU-acquired weakness and being deactivated from the transplant list (19). By extension, participation in physical activity while awaiting transplantation may mitigate deconditioning and help maintain transplant candidacy $(18,20)$. Several cohort studies and case series have demonstrated the feasibility and safety of a strategy that maximizes the opportunity for mobilization, particularly
Salna et al. Mobilization of awake patients on extracorporeal support

when active physical therapy is combined with an awake and endotracheally extubated approach (21-23). A recent cohort study of 121 ECMO BTT patients found that ambulation was an independent predictor of successful transplantation (OR 7.6, 95\% CI: 2.2-26.6, $\mathrm{P}=0.002$ ) (24), and a study by Benazzo et al. of $120 \mathrm{BTT}$ patients also determined that being awake during ECMO as BTT was associated with improved survival in a multivariable model $(24,25)$. A subgroup of ECMOsupported patients awaiting lung transplantation who are perhaps more comparable to the cardiac BTT population are those with pulmonary hypertension and associated right heart failure who receive venoarterial ECMO almost exclusively. A retrospective cohort study of patients with interstitial lung disease and concomitant pulmonary hypertension likewise found an association between pre-transplantation ambulation during ECMO and a reduced risk of death (HR 0.20, 95\% confidence interval: 0.08 to $0.48, \mathrm{P}<0.01)(26)$.

It may be difficult to extrapolate the data for ECMO as BTT in lung transplantation to those who are awaiting heart transplantation-with ECMO or other TCS as BTT — for several reasons, including anticipated wait times and the relative importance placed on physical fitness pretransplantation. With the allocation of donor hearts recently changing in the United States, as an example, such that those receiving ECMO have been given highest priority for transplantation (27), it is possible these patients will not have time or the opportunity to engage in meaningful rehabilitation before transplantation, and that transplant candidacy will not necessarily hinge on their ability to perform active physical therapy during ECMO. That being said, case series have demonstrated the safe and successful use of ambulatory ECMO as a bridge to heart transplantation (28-31), as well as with the Impella 5.0 (32). Likewise, Tanaka et al. demonstrated the successful use of IABPs implanted in the right subclavian artery as a BTT in 61 patients, achieving ambulation in $96 \%$ of their overall cohort with a $26 \%$ IABP exchange rate-mostly due to kinked drivelines during mobilization (33). It must be noted that in all of these series, there was no evaluation performed of any association between ambulation and successful transplantation, suggesting the need for robust studies to assess these outcomes.

In contrast to other forms of TCS, a benefit of ECMO is the potential to liberate select patients from IMV by supporting gas exchange (Figure 1). Although mobilization has long been feasible with IMV $(4,34)$, its removal in the context of ECMO simply increases the feasibility of mobilization. The pre-transplant use of IMV, regardless of etiology, has traditionally been associated with worse post- 
transplant outcomes when compared with patients not requiring IMV $(35,36)$, in large part reflecting the severity of illness in this cohort. In addition to the inherent risks of IMV-including ventilator-associated pneumonia and ventilator-induced lung injury-reliance on the mechanical ventilator for gas exchange may at times be associated with increased sedation requirements or the need for neuromuscular blocking agents, limiting the potential for mobilization (37). Furthermore, the presence of the ventilator alone may not alleviate dyspnea or respiratory effort even when gas exchange is normalized, something that may be better managed with ECMO under some circumstances $(38,39)$. Unlike patients with primarily severe respiratory failure, there is perhaps greater potential for ECMO-supported cardiogenic shock patients to be liberated from or avoid IMV, as their respiratory failure, if present, may be less severe or sufficiently managed with support of their underlying cardiac failure (e.g., in the case of pulmonary edema). In patients who have an ongoing need for IMV in combination with ECMO, early mobilization remains feasible (40), although tracheostomy may be considered in selected patients in order to improve comfort, facilitate minimization of sedation, and possibly increase the likelihood of successful ambulation. Tracheostomy during ECMO has been found to be safe, but the optimal timing and indications have yet to be established (41).

\section{Bridge to recovery}

Patients receiving TCS for cardiac failure as BTR may also be candidates for early mobilization, although there is essentially no data on the impact of early mobilization on outcomes in this population. Likewise, mobilization in patients supported with short-term surgical VADs with apical-axillary cannulation or conventional biventricular VADs, has been described. However, the effect of these strategies has yet to be determined (16,31). In the realm of $\mathrm{ECMO}$, the existing data from patients receiving ECMO for respiratory failure offers some insight into the potential role of an awake, ambulatory strategy in cardiac failure patients $(40,42,43)$, but it is important to recognize the limitations of such comparisons and the lack of proven benefit from early mobilization even within the respiratory population.

\section{Importance of cannula and device components in mobilization and rehabilitation}

When considering the feasibility and safety of mobilizing patients receiving TCS or respiratory ECMO, one must take into account the limitations imposed by the device components such as drivelines or cannulae as well as how the location of these components may impact successful mobilization. For example, peripheral femoral venous to femoral arterial cannulation is the most common approach for venoarterial ECMO, given the ability to perform it quickly at the bedside, in the operating room, or in the cardiac catheterization lab, as is often necessary for ECMO cannulation for cardiogenic shock (44). Similarly, percutaneous insertion of left-sided Impellas or IABPs is traditionally performed via the femoral arteries. In contrast to these devices, however, where mobilization is not recommended due to precise positioning, the presence of femoral ECMO cannulae is not a barrier to mobilization to the same degree, and several reports have demonstrated the safety of ambulation with femoral cannulae $(28,40,45,46)$. That being said, any center considering early mobilization of patients with femoral cannulae should have sufficient experience in ECMO mobilization given the potential risk for dislodgement. Much like the axillary IABP or Impella, a variety of upper-body ECMO configurations have been described where there is a desire to avoid femoral cannulation for ease of mobilization (13).

In cases of significant gas exchange impairment, an additional venous reinfusion limb may be spliced into the existing femoral-femoral venoarterial circuit to improve upper-body oxygenation (venoarterial-venous ECMO) (47). Notably, this strategy may complicate mobilization given the additional cannula and the potential need for more total ECMO blood flow in order to achieve adequate blood flow through each reinfusion cannula. Some central cannulation techniques provide an alternative option to achieve adequate upper-body oxygenation while facilitating mobilization. Internal jugular venous drainage combined with ipsilateral subclavian, axillary, or innominate arterial reinfusion (48-50), right atrial drainage with aortic reinfusion $(51,52)$, and left ventricular drainage with axillary arterial reinfusion (31) are all examples of cannulation strategies that may support patients with cardiogenic shock via an upper-body approach, although difficulty with ambulation will vary by technique and by the individual patient. However, because many of these approaches require a sternotomy or a thoracotomy, they carry particular risks not seen with peripheral cannulation, such as bleeding or infection within the mediastinum (53-55).

Pulmonary hypertension and RV failure, in the absence of left-sided heart failure, offers unique opportunities for ECMO cannulation strategies that may likewise facilitate 
mobilization. Some of the same strategies for cardiogenic shock with $L V$ failure have been described in the pulmonary hypertension population, including the subclavian, axillary and innominate reinfusion approaches (48-50,52). In select cases, and with certain approaches, anesthetic induction and intubation may be avoided entirely at the time of cannulation, which may help to minimize the risk of circulatory collapse associated with induction and endotracheal intubation in this high-risk population (56). An alternative central approach for these patients consists of pulmonary arterial drainage to left atrial reinfusion, which may not require the use of an extracorporeal pump (57). In patients with pulmonary hypertension who have a preexisting inter-atrial communication (e.g., atrial septal defect or sufficiently large patent foramen ovale), consideration might be given to the use of a bicaval dual-lumen cannula inserted through the internal jugular vein where the reinfusion jet is directed across the defect. This method facilitates RV decompression, creates an oxygenated right-to-left shunt, and avoids femoral cannulation while still offering a percutaneous approach (58-60). Select patients without a pre-existing arterial septal defect may be candidates for the creation of an atrial septostomy to facilitate such a strategy (61).

Beyond cannulation configuration, the ability to mobilize ECMO circuitry itself (e.g., pump, membrane lung, gas supply, console, tubing) must also be taken into consideration. Advances in extracorporeal circuitry, which have included increasingly compact circuits with integrated pumps, membrane lungs, and consoles, have made it easier to mobilize and ambulate ECMO patients $(40,62,63)$.

\section{Special considerations for rehabilitation in TCS and respiratory ECMO patients}

\section{Cannula-related risks}

Any attempts at mobilizing patients receiving ECMO must weigh the potential risks with anticipated benefits. The most important consideration during physical rehabilitation of these patients is ensuring that therapy does not jeopardize patient safety through compromising the integrity of the cannulae or circuit. ECMO cannulae and tubing are at risk for malposition, kinking and dislodgement or disconnection during mobilization. Despite wire reinforcement within the cannula, activities involving hip flexion in patients with femoral cannulation, or other cannula manipulation, may still result in bends or kinks in the cannulae, which may interrupt blood flow. Arterial reinfusion cannulae tend to be shorter than drainage cannulae and are therefore at greater potential risk for dislodgement. It is imperative that providers confirm cannulae are well-secured with either sutures or securement straps prior to any mobilization, while closely monitoring blood flow and line pressures during activity.

\section{Patients with more than one device}

Many patients receiving ECMO for cardiogenic shock may have additional TCS devices, such as IABPs or an Impella, to assist in left ventricular decompression, which may increase risks associated with mobilization, or they may have these devices alone without ECMO. As described earlier, IABPs and percutaneous TCS devices require precise positioning for optimal function and will be at risk for dislodgement with patient movement, particularly with outof-bed activities. While the presence of these devices does not necessarily preclude any attempt at mobilization, the serious added risk of malpositioning or dislodgement must be weighed against any potential benefits of mobilization. If limited physical therapy is performed, practitioners must ensure proper securement prior to and throughout the session. A potential solution to reduce the risk of malposition is the insertion of these devices via the axillary or subclavian artery, which may further facilitate ambulation $(8,9,64)$, if that is otherwise appropriate for the patient.

\section{Physiologic demand}

An important aspect of mobilization of ECMO patients is the increased physiologic demand generated during physical rehabilitation. Similarly, patients receiving ECMO may experience worsening gas exchange or hemodynamics depending on the extent of physical therapy in the context of the patient's underlying organ dysfunctions. Both hemodynamics and respiratory status should be monitored closely throughout therapy sessions, with increases in extracorporeal blood flow (for oxygenation or hemodynamic support, depending on the configuration), and sweep gas flow (for increased ventilatory needs), or inotropic or vasopressor support, provided as needed. If mobilization is anticipated prior to cannulation, consideration should also be made for cannula sizes that can accommodate increases in extracorporeal blood flow to meet patients' needs during therapy. Likewise, patients with short-term VADs are more readily mobilized with closed chests and secured, tunneled cannulae. 


\section{Contraindications}

Circumstances in which the risks of physical therapy likely outweigh the benefits in patients receiving TCS or ECMO are situations of clinical instability, including but not limited to clinically significant hemorrhage, unstable arrhythmias, hemodynamic instability requiring moderateto-high-dose (or recently escalating) vasopressors, and severe hypoxemia or acidemia. Similarly, physical therapy should be discontinued if patients become unstable during activity. Patients who are deemed too clinically unstable for early mobilization may continue to undergo daily (or more frequent) assessments to determine appropriateness to reconsider mobilization or may be appropriate for in-bed exercises or passive range of motion.

\section{The importance of an interprofessional team approach}

An integral part of any awake, mobile strategy during mechanical cardiorespiratory support is an interprofessional team approach (40). Collaboration between all providers, including nurses, physical and occupational therapists, respiratory therapists, perfusionists, surgeons, cardiologists and intensivists, among others on the team, with welldefined roles, is essential to ensure safety and success of early mobilization $(42,43,65)$.

\section{Conclusions}

Early mobilization has been shown to be safe and beneficial in patients receiving ECMO for respiratory failure, particularly in patients receiving ECMO as a bridge to lung transplantation, when conducted meticulously at centers with experience in mobilizing ECMO patients. While mobilization may likewise be considered for patients receiving ECMO or other forms of TCS for cardiac failure, the specific patient populations most likely to benefit from these interventions have yet to be defined. Regardless of which patients are considered for early mobilization, an interprofessional team approach with well-defined roles and responsibilities, along with careful patient selection are essential to ensure safe and successful rehabilitation in this critically ill patient population.

\section{Acknowledgments}

Funding: None.

\section{Footnote}

Provenance and Peer Review: This article was commissioned by the Guest Editor (Kamen Valchanov) for the Series "Perioperative Management of Patients with undergoing Mechanical Circulatory Support" published in Annals of Translational Medicine. The article was sent for external peer review organized by the Guest Editor and the editorial office.

Conflicts of Interest: All authors have completed the ICMJE uniform disclosure form (available at http://dx.doi. org/10.21037/atm.2020.03.151). The series "Perioperative Management of Patients with undergoing Mechanical Circulatory Support" was commissioned by the editorial office without any funding or sponsorship. DB offers research support to ALung Technologies and is on the medical advisory boards of Baxter, BREETHE, Hemovent, and Xenios. The authors have no other conflicts of interest to declare.

Ethical Statement: The authors are accountable for all aspects of the work in ensuring that questions related to the accuracy or integrity of any part of the work are appropriately investigated and resolved.

Open Access Statement: This is an Open Access article distributed in accordance with the Creative Commons Attribution-NonCommercial-NoDerivs 4.0 International License (CC BY-NC-ND 4.0), which permits the noncommercial replication and distribution of the article with the strict proviso that no changes or edits are made and the original work is properly cited (including links to both the formal publication through the relevant DOI and the license). See: https://creativecommons.org/licenses/by-nc-nd/4.0/.

\section{References}

1. Herridge MS, Tansey CM, Matte A, et al. Functional disability 5 years after acute respiratory distress syndrome. N Engl J Med 2011;364:1293-304.

2. Needham DM. Mobilizing patients in the intensive care unit: improving neuromuscular weakness and physical function. JAMA 2008;300:1685-90.

3. Berg HE, Larsson L, Tesch PA. Lower limb skeletal muscle function after $6 \mathrm{wk}$ of bed rest. J Appl Physiol (1985) 1997;82:182-8.

4. Schweickert WD, Pohlman MC, Pohlman AS, et al. 
Early physical and occupational therapy in mechanically ventilated, critically ill patients: a randomised controlled trial. Lancet 2009;373:1874-82.

5. Tipping CJ, Harrold M, Holland A, et al. The effects of active mobilisation and rehabilitation in ICU on mortality and function: a systematic review. Intensive Care Med 2017;43:171-83.

6. Morris PE, Goad A, Thompson C, et al. Early intensive care unit mobility therapy in the treatment of acute respiratory failure. Crit Care Med 2008;36:2238-43.

7. Nydahl P, Sricharoenchai T, Chandra S, et al. Safety of Patient Mobilization and Rehabilitation in the Intensive Care Unit. Systematic Review with Meta-Analysis. Ann Am Thorac Soc 2017;14:766-77.

8. Estep JD, Cordero-Reyes AM, Bhimaraj A, et al. Percutaneous placement of an intra-aortic balloon pump in the left axillary/subclavian position provides safe, ambulatory long-term support as bridge to heart transplantation. JACC Heart Fail 2013;1:382-8.

9. Esposito ML, Jablonski J, Kras A, et al. Maximum level of mobility with axillary deployment of the Impella 5.0 is associated with improved survival. Int J Artif Organs 2018;41:236-9.

10. Kar B, Gregoric ID, Basra SS, et al. The percutaneous ventricular assist device in severe refractory cardiogenic shock. J Am Coll Cardiol 2011;57:688-96.

11. Ravichandran AK, Baran DA, Stelling K, et al. Outcomes with the Tandem Protek Duo Dual-Lumen Percutaneous Right Ventricular Assist Device. ASAIO J 2018;64:570-2.

12. Coromilas EJ, Takeda K, Ando M, et al. Comparison of Percutaneous and Surgical Right Ventricular Assist Device Support After Durable Left Ventricular Assist Device Insertion. J Card Fail 2019;25:105-13.

13. Brodie D, Slutsky AS, Combes A. Extracorporeal Life Support for Adults With Respiratory Failure and Related Indications: A Review. JAMA 2019;322:557-68.

14. Takayama H, Chen JM, Jorde UP, et al. Implantation technique of the CentriMag biventricular assist device allowing ambulatory rehabilitation. Interact Cardiovasc Thorac Surg 2011;12:110-1.

15. Tribble C, Urencio M, Aru G, et al. A technique for implantation of the CentriMag left ventricular assist device to allow ambulation and rehabilitation in patients with heart failure. Heart Surg Forum 2015;18:E081-3.

16. McGarrigle L, Caunt J. Physical Therapist-Led Ambulatory Rehabilitation for Patients Receiving CentriMag Short-Term Ventricular Assist Device Support: Retrospective Case Series. Physical Therapy
2016;96:1865-73.

17. Australian and New Zealand Intensive Care Research Centre. Extracorporeal Membrane Oxygenation Physical Training (ECMO-PT). In: ClinicalTrials.gov [Internet]. Bethesda (MD): National Library of Medicine (US) 2000[cited 2018 Apr 10]. Available online: http://clinicaltrials. gov/ct2/show/NCT03328767. NLM Identifier: NCT03328767.

18. Weill D, Benden C, Corris PA, et al. A consensus document for the selection of lung transplant candidates: 2014--an update from the Pulmonary Transplantation Council of the International Society for Heart and Lung Transplantation. J Heart Lung Transplant 2015;34:1-15.

19. Hayes K, Hodgson CL, Pellegrino VA, et al. Physical Function in Subjects Requiring Extracorporeal Membrane Oxygenation Before or After Lung Transplantation. Respir Care 2018;63:194-202.

20. Abrams D, Brodie D, Arcasoy SM. Extracorporeal Life Support in Lung Transplantation. Clin Chest Med 2017;38:655-66.

21. Biscotti M, Gannon WD, Agerstrand C, et al. Awake Extracorporeal Membrane Oxygenation as Bridge to Lung Transplantation: A 9-Year Experience. Ann Thorac Surg 2017;104:412-9.

22. Fuehner T, Kuehn C, Hadem J, et al. Extracorporeal membrane oxygenation in awake patients as bridge to lung transplantation. Am J Respir Crit Care Med 2012;185:763-8.

23. Hoopes CW, Kukreja J, Golden J, et al. Extracorporeal membrane oxygenation as a bridge to pulmonary transplantation. J Thorac Cardiovasc Surg 2013;145:862-7.

24. Tipograf Y, Salna M, Minko E, et al. Outcomes of Extracorporeal Membrane Oxygenation as a Bridge to Lung Transplantation. Ann Thorac Surg 2019;107:1456-63.

25. Benazzo A, Schwarz S, Frommlet F, et al. Twenty-year experience with extracorporeal life support as bridge to lung transplantation. J Thorac Cardiovasc Surg 2019;157:2515-25.e10.

26. Chicotka S, Pedroso FE, Agerstrand CL, et al. Increasing Opportunity for Lung Transplant in Interstitial Lung Disease with Pulmonary Hypertension. Ann Thorac Surg 2018;106:1812-19.

27. Network OPaT. Criteria Requirements in Adult Heart Allocation Policy 2017 Available online: https://optn. transplant.hrsa.gov/media/2413/adult_heart_criteria.pdf

28. Shudo Y, Kasinpila P, Lee AM, et al. Ambulating femoral venoarterial extracorporeal membrane oxygenation bridge to heart-lung transplant. J Thorac Cardiovasc Surg 
2018;156:e135-7.

29. Shudo Y, Wang H, Ha RV, et al. Heart transplant after profoundly extended ambulatory central venoarterial extracorporeal membrane oxygenation. J Thorac Cardiovasc Surg 2018;156:e7-9.

30. Takeda K, Garan AR, Ando M, et al. Minimally invasive CentriMag ventricular assist device support integrated with extracorporeal membrane oxygenation in cardiogenic shock patients: a comparison with conventional CentriMag biventricular support configuration. Eur J Cardiothorac Surg 2017;52:1055-61.

31. Takeda K, Garan AR, Topkara VK, et al. Novel minimally invasive surgical approach using an external ventricular assist device and extracorporeal membrane oxygenation in refractory cardiogenic shock. Eur J Cardiothorac Surg 2017;51:591-6.

32. Lima B, Kale P, Gonzalez-Stawinski GV, et al. Effectiveness and Safety of the Impella 5.0 as a Bridge to Cardiac Transplantation or Durable Left Ventricular Assist Device. Am J Cardiol 2016;117:1622-8.

33. Tanaka A, Tuladhar SM, Onsager D, et al. The Subclavian Intraaortic Balloon Pump: A Compelling Bridge Device for Advanced Heart Failure. Ann Thorac Surg 2015;100:2151-7.

34. Bailey P, Thomsen GE, Spuhler VJ, et al. Early activity is feasible and safe in respiratory failure patients. Crit Care Med 2007;35:139-45.

35. Mason DP, Thuita L, Nowicki ER, et al. Should lung transplantation be performed for patients on mechanical respiratory support? The US experience. J Thorac Cardiovasc Surg 2010;139:765-73.e1.

36. Toyoda Y, Bhama JK, Shigemura N, et al. Efficacy of extracorporeal membrane oxygenation as a bridge to lung transplantation. J Thorac Cardiovasc Surg 2013;145:1065-71.

37. Abrams D, Brodie D. Emerging indications for extracorporeal membrane oxygenation in adults with respiratory failure. Ann Am Thorac Soc 2013;10:371-7.

38. Abrams DC, Brenner K, Burkart KM, et al. Pilot study of extracorporeal carbon dioxide removal to facilitate extubation and ambulation in exacerbations of chronic obstructive pulmonary disease. Ann Am Thorac Soc 2013;10:307-14.

39. Crotti S, Bottino N, Ruggeri GM, et al. Spontaneous Breathing during Extracorporeal Membrane Oxygenation in Acute Respiratory Failure. Anesthesiology 2017;126:678-87.

40. Abrams D, Javidfar J, Farrand E, et al. Early mobilization of patients receiving extracorporeal membrane oxygenation: a retrospective cohort study. Crit Care 2014;18:R38.

41. Salna M, Tipograf Y, Liou P, et al. Tracheostomy Is Safe During Extracorporeal Membrane Oxygenation Support. ASAIO J 2020;66:652-6.

42. Wells CL, Forrester J, Vogel J, et al. Safety and Feasibility of Early Physical Therapy for Patients on Extracorporeal Membrane Oxygenator: University of Maryland Medical Center Experience. Crit Care Med 2018;46:53-9.

43. Munshi L, Kobayashi T, DeBacker J, et al. Intensive Care Physiotherapy during Extracorporeal Membrane Oxygenation for Acute Respiratory Distress Syndrome. Ann Am Thorac Soc 2017;14:246-53.

44. Abrams D, Garan AR, Abdelbary A, et al. Position paper for the organization of ECMO programs for cardiac failure in adults. Intensive Care Med 2018;44:717-29.

45. Perme C, Nalty T, Winkelman C, et al. Safety and Efficacy of Mobility Interventions in Patients with Femoral Catheters in the ICU: A Prospective Observational Study. Cardiopulm Phys Ther J 2013;24:12-7.

46. Pasrija C, Mackowick KM, Raithel M, et al. Ambulation With Femoral Arterial Cannulation Can Be Safely Performed on Venoarterial Extracorporeal Membrane Oxygenation. Ann Thorac Surg 2019;107:1389-94.

47. Biscotti M, Lee A, Basner RC, et al. Hybrid Configurations via Percutaneous Access for Extracorporeal Membrane Oxygenation: A Single Center Experience. ASAIO J 2014;60:635-42.

48. Javidfar J, Brodie D, Costa J, et al. Subclavian artery cannulation for venoarterial extracorporeal membrane oxygenation. ASAIO J 2012;58:494-8.

49. Biscotti M, Bacchetta M. The "sport model": extracorporeal membrane oxygenation using the subclavian artery. Ann Thorac Surg 2014;98:1487-9.

50. Chicotka S, Rosenzweig EB, Brodie D, et al. The "Central Sport Model": Extracorporeal Membrane Oxygenation Using the Innominate Artery for Smaller Patients as Bridge to Lung Transplantation. ASAIO J 2017;63:e39-44.

51. Donker DW, Brodie D, Henriques JPS, et al. Left Ventricular Unloading During Veno-Arterial ECMO: A Simulation Study. ASAIO J 2019;65:11-20.

52. Downey P, Ragalie W, Gudzenko V, et al. Ambulatory central veno-arterial extracorporeal membrane oxygenation in lung transplant candidates. J Heart Lung Transplant 2019;38:1317-9.

53. Raffa GM, Kowalewski M, Brodie D, et al. Meta-Analysis of Peripheral or Central Extracorporeal Membrane 
Oxygenation in Postcardiotomy and Non-Postcardiotomy

Shock. Ann Thorac Surg 2019;107:311-21.

54. Schmidt M, Brechot N, Hariri S, et al. Nosocomial infections in adult cardiogenic shock patients supported by venoarterial extracorporeal membrane oxygenation. Clin Infect Dis 2012;55:1633-41.

55. Abrams D, Grasselli G, Schmidt M, et al. ECLS-associated infections: what we know and what we don't yet know. Intensive Care Med 2020;46:182-91.

56. Biscotti M, Vail E, Cook KE, et al. Extracorporeal Membrane Oxygenation with Subclavian Artery Cannulation in Awake Patients with Pulmonary Hypertension. ASAIO J 2014;60:748-50.

57. Strueber M, Hoeper MM, Fischer S, et al. Bridge to thoracic organ transplantation in patients with pulmonary arterial hypertension using a pumpless lung assist device. Am J Transplant 2009;9:853-7.

58. Javidfar J, Brodie D, Sonett J, et al. Venovenous extracorporeal membrane oxygenation using a single cannula in patients with pulmonary hypertension and atrial septal defects. J Thorac Cardiovasc Surg 2012;143:982-4.

59. Abrams DC, Brodie D, Rosenzweig EB, et al. Upperbody extracorporeal membrane oxygenation as a strategy in decompensated pulmonary arterial hypertension. Pulm
Circ 2013;3:432-5.

60. Rosenzweig EB, Brodie D, Abrams DC, et al. Extracorporeal membrane oxygenation as a novel bridging strategy for acute right heart failure in group 1 pulmonary arterial hypertension. ASAIO J 2014;60:129-33.

61. Hoopes CW, Gurley JC, Zwischenberger JB, et al. Mechanical support for pulmonary veno-occlusive disease: combined atrial septostomy and venovenous extracorporeal membrane oxygenation. Semin Thorac Cardiovasc Surg 2012;24:232-4.

62. Lehle K, Philipp A, Hiller KA, et al. Efficiency of gas transfer in venovenous extracorporeal membrane oxygenation: analysis of 317 cases with four different ECMO systems. Intensive Care Med 2014;40:1870-7.

63. Abrams D, Combes A, Brodie D. Extracorporeal Membrane Oxygenation in Cardiopulmonary Disease in Adults. J Am Coll Cardiol 2014;63:2769-78.

64. Bertoldi LF, Bertoglio L, Pappalardo F. Concomitant use of Impella while on peripheral veno-arterial extracorporeal membrane oxygenation: de-escalate and ambulate. Ann Cardiothorac Surg 2019;8:160-2.

65. Abrams D, Garan AR, Brodie D. Awake and fully mobile patients on cardiac extracorporeal life support. Ann Cardiothorac Surg 2019;8:44-53.
Cite this article as: Salna M, Abrams D, Brodie D. Physical rehabilitation in the awake patient receiving extracorporeal circulatory or gas exchange support. Ann Transl Med 2020;8(13):834. doi: 10.21037/atm.2020.03.151 